adenosine triphosphatase. Ann. N. Y. Acad. Sci., 273: 331 (1976)

17. Lin, G. W. J.: Effect of ethanol feeding during pregnancy on placental transfer of alpha-amino isobutyric acid in the rat. Life Sci., 28: 595 (1981).

18. Mann, L. 1.: Bhakthavanthsalan, A., Liu, M., and Makowski, P.: Placental transport of alcohol and its effect on maternal and fetal acidbase balance. Am. J. Obstet. Gynecol., 122: 837 (1975).

19. Miller, R. K. and Berndt, W. D.: Mechanisms of transport across the placenta: An in vitro approach. Life Sci., 16: 7 (1975).

20. Munro, H. N.: Placenta in relation to nutrition. Fed. Proc., 39: 236 (1980)

21. Ouellette, E. M., Rosett, H. L., Rosman, N. P., and Weiner, L.: Adverse effects on offspring of maternal alcohol abuse during pregnancy. New Engl. J. Med. 297: 528 (1977).

22. Patwardhan, R. V., Schenker, S., Henderson, G. I., Abou-Mourad, N. N., and Hoyumpa, A. M.: Short-term and long-term ethanol administration inhibits the plecental uptake and transport of valine in rats. J. Lab. Clin. Med., 98: 251 (1981).

23. Rawat, A. K.: Effect of maternal ethanol consumption on foetal and neonatal rat hepatic protein synthesis. Biochem. J., 160: 653 (1976).

24. Smith, C. H., Adcock, E. W., Teasdale, F., Meschia, G., and Bataglia, F. C.:
Placental amino acid uptake: Tissue preparation, kinetics, and preincubation effect. Am. J, Physiol., 224: 558 (1973).

25. Sokol, A. J., Miller, S. I., and Reed, G. Alcohol Abuse During Pregnancy. An Epidemiological Model. Alcoholism. Clin. Exp. Res. 4: 135 (1980).

26. Sulik, K., Johntton, M. D., and Webb, M. A.: Fetal Alcohol Syndrome: Embryogenesis in a Mouse Model. Science. 214: 936 (1981).

27. Wunderlich, S. M., Baliga, B. S., and Munro, H. N.: Rat Placental Protein Synthesis an Peptide Hormone Secretion in Reiation to Malnutrition from Protein Deficiency or Alcohol Administration. J. Nutr. 109: 1534 (1979).

28. The authors with to thank Dr. Fima Lifshitz for reviewing the manuscript and to acknowledge the secretarial assistance of Ms. Silvana Palmieri and Ms. Cathleen Callaghan.

29. Requests for reprints should be addressed to: Dr. Stanley E. Fisher, North Shore University Hospital, Department of Pediatrics, 300 Community Drive, Manhasset, NY 11030.

30. Supported, in part, by grants from the Hagan Foundation, the Hunt Foundation, and the National Institutes of Health (AA 03920 and AA 04425).

31. Received for publication June 3, 1982.

32. Accepted for publication December 9, 1982.

$0031-3998 / 83 / 1709-0707 \$ 02.00 / 0$

PEDIATRIC RESEARCH

Copyright @ 1983 International Pediatric Research Foundation, Inc.

Vol. 17, No. 9,1983

Printed in U.S.A.

\title{
Developmental Pattern of Maximal Transdiaphragmatic Pressure in Infants during Crying
}

\author{
CHARLES B. SCOTT, BRUCE G. NICKERSON, ${ }^{(15)}$ CHARLES W. SARGENT, \\ ARNOLD C. G. PLATZKER, DAVID WARBURTON, AND THOMAS G. KEENS ${ }^{(18)}$ \\ Neonatal-Respiratory Disease Division, Department of Pediatrics, Childrens Hospital of Los Angeles and the \\ University of Southern California School of Medicine, Los Angeles, California, USA
}

\section{Summary}

Diaphragm strength was measured as maximal transdiaphragmatic pressure (Pdi) during airway occlusion in 38 infants aged $11.6 \pm 0.5$ (S.E.) months postconception (mpc), range 8-21 mpc. All infants were asymptomatic at the time of study and required no mechanical ventilatory assistance. Ten infants had previous surgical correction of abdominal wall defects (gastroschisis/omphalocele); 10 infants had previous surgical correction of congenital diaphragmatic hernia; and 18 infants had no thoracic or abdominal surgery. The mean maximal Pdi for all infants was 72 $\pm 3 \mathrm{cmH}_{2} \mathrm{O}$. There were no significant differences between the three groups. All infants with a maximal Pdi of less than 60 $\mathrm{cmH}_{2} \mathrm{O}$ were aged less than 10 mpc. After 13 mpc there was no significant increase in maximal Pdi. Between the ages 8-13 mpc there was a significant positive correlation between maximal Pdi and age postconception $(r=0.87, P<0.0005$ ), reflecting a developmental pattern of increasing maximal transdiaphragmatic pressure in infants during crying.

\section{Abbreviations}

mpc, months postconception

Pdi, maximal transdiaphragmatic pressure

Premature infants have incomplete growth and development of skeletal muscle. A lack of muscle mass is visibly evident in most premature infants, suggesting decreased muscle power. One might assume that diaphragmatic muscle strength is similarly decreased, yet it has not been measured in infants. Diaphragmatic fatigue, detected by power frequency spectral analysis of the diaphragm electromyogram, has been shown to occur in preterm infants $(9$, 11). Diaphragm fatigue has also been shown to be an important variable in the successful weaning of infants from assisted ventilation (11). Roussos and Macklem (13) have shown that the diaphragm in normal adults will fatigue if greater than $40 \%$ of maximal transdiaphragmatic pressure is required on each breath. This \% may be even less in infants because of the lower proportion of fatigue-resistant muscle fibers in their diaphragms (6); however, the work of breathing in infants is high. Because respiratory failure may occur when there is insufficient ventilatory muscle power to overcome increased respiratory loads, decreased diaphragm power or strength as well as endurance may predispose infants to respiratory failure. If the diaphragm has insufficient strength to overcome increased respiratory loads, fatigue will clearly occur (12, 13). In this study, the developmental pattern of maximal transdiaphragmatic pressure was determined to assess the relative susceptibility of the diaphragm to fatigue in infants.

\section{MATERIALS AND METHODS}

Maximal transdiaphragmatic pressures were measured in 38 infants who were asymptomatic, breathing spontaneously, had normal blood gases, and required no mechanical ventilatory assistance. None of the infants demonstrated hyperinflation on chest roentgenograms at the time of study. Informed consent was obtained from parehts of all infants before study, and the study was approved by the institutional review board.

The age range for the entire group was from $8 \mathrm{mpc}$, or $36 \mathrm{wk}$ estimated gestational age, to $21 \mathrm{mpc}$, or 12 months post-fullterm, with a mean of $11.6 \pm 0.5$ (S.E.) mpc.

The patient population was comprised of three groups. The first 
was composed of 10 infants, aged $11.3 \pm 0.9 \mathrm{mpc}$, who had previous surgical correction of abdominal wall defects (either gastroschisis or omphalocele). The second was composed of 10 infants, aged $12.4 \pm 1.2 \mathrm{mpc}$, who had previous surgical correction of congenital diaphragmatic hernia. All of these infants were studied at least 1 wk after surgery. The third was composed of 18 control infants, aged $11.2 \pm 0.8 \mathrm{mpc}$, who had no thoracic or abdominal surgery. These were generally preterm infants who did not have significant lung disease at the time of study. There were no significant differences in the ages of the different groups $(P=$ 0.96).

Transdiaphragmatic pressure was measured according to the method of Agostoni (1, 2). A double-lumen (PE 200 Tubing, 100 $\mathrm{cm}$ long) catheter was swallowed with one $6-\mathrm{cm}$ balloon inflated with $0.1 \mathrm{ml}$ of air being positioned in the mid-esophagus to measure intrathoracic pressure. Accuracy of measurement was confirmed by comparison of intrathoracic pressure with mouth pressure during airway occlusion (3). The other $6-\mathrm{cm}$ balloon inflated with $1.0 \mathrm{ml}$ of air was positioned in the stomach to measure intragastric pressure, an approximation of intra-abdominal pressure. These balloon gas volumes were within the working range of pressure-volume curves determined in vitro for each balloon (3). The balloons were connected to a differential pressure transducer. To correct for the difference between intragastric pressure and intra-abdominal pressure immediately beneath the diaphragm, Pdi was assumed to be zero at end expiration during quiet breathing.

Transdiaphragmatic pressure was recorded during spontaneous respirations, while crying, and during airway occlusion. Maximal

Table 1. Maximal transdiaphragmatic pressures in infants after repair of abdominal wall defects

\begin{tabular}{ccccc}
\hline No. & Sex & $\begin{array}{c}\text { Postconceptional } \\
\text { age } \\
\text { (months) }\end{array}$ & $\begin{array}{c}\text { Postnatal } \\
\text { age } \\
\text { (months) }\end{array}$ & $\begin{array}{c}\text { Max } \\
\mathbf{P d i}^{1} \\
\text { (cmH2) }\end{array}$ \\
\hline 1 & F & 8.5 & 0.5 & 45 \\
2 & M & 9.3 & 1.0 & 56 \\
3 & M & 9.5 & 1.0 & 70 \\
4 & M & 9.8 & 0.8 & 65 \\
5 & F & 9.8 & 0.8 & 82 \\
6 & F & 10.5 & 1.7 & 75 \\
7 & F & 10.5 & 1.7 & 76 \\
8 & F & 12.5 & 5.0 & 125 \\
9 & F & 16.0 & 7.5 & 106 \\
10 & F & 17.0 & 8.0 & 89
\end{tabular}

Mean \pm S.E.

$11.3 \pm 0.9$

$2.8 \pm 0.9$

$79 \pm 7$

'Max Pdi, maximal transdiaphragmatic pressure.

Table 2. Maximal transdiaphragmatic pressures in infants after repair of congenital diaphragmatic hernia

\begin{tabular}{|c|c|c|c|c|}
\hline No. & Sex & $\begin{array}{c}\text { Postconceptional } \\
\text { age } \\
\text { (months) }\end{array}$ & $\begin{array}{l}\text { Postnatal } \\
\text { age } \\
\text { (months) }\end{array}$ & $\begin{array}{c}\mathrm{Max} \\
\mathrm{Pdi} \\
\left(\mathrm{cmH}_{2} \mathrm{O}\right)\end{array}$ \\
\hline 1 & $\mathbf{M}$ & 8.8 & 0.3 & 56 \\
\hline 2 & $\mathbf{M}$ & 9.3 & 0.8 & 45 \\
\hline 3 & $\mathbf{M}$ & 9.3 & 0.5 & 48 \\
\hline 4 & $\mathbf{M}$ & 9.8 & 1.0 & 76 \\
\hline 5 & $\mathbf{F}$ & 10.0 & 1.0 & 59 \\
\hline 6 & $\mathbf{F}$ & 12.5 & 3.5 & 99 \\
\hline 7 & $\mathbf{M}$ & 13.0 & 4.0 & 88 \\
\hline 8 & $\mathbf{M}$ & 14.3 & 5.5 & 71 \\
\hline 9 & $\mathbf{M}$ & 16.5 & 7.5 & 85 \\
\hline 10 & $\mathbf{M}$ & 21.0 & 12.0 & 81 \\
\hline
\end{tabular}

Mean \pm S.E.

$12.4 \pm 1.2 \quad 3.6 \pm 1.2$ $71 \pm 6$

'Max Pdi, maximal transdiaphragmatic pressure.
Table 3. Maximal transdiaphragmatic pressure in control infants

\begin{tabular}{rlccc}
\hline No. & Sex & $\begin{array}{c}\text { Postconceptional } \\
\text { age } \\
\text { (months) }\end{array}$ & $\begin{array}{c}\text { Postnatal } \\
\text { age } \\
\text { (months) }\end{array}$ & $\begin{array}{c}\text { Max } \\
\text { Pdi }^{1} \\
\left(\mathbf{c m H}_{2} \text { O) }\right.\end{array}$ \\
\hline 1 & M & 8.0 & 1.7 & 44 \\
2 & M & 8.0 & 1.3 & 47 \\
3 & M & 8.8 & 2.3 & 72 \\
4 & M & 9.0 & 0.5 & 52 \\
5 & F & 9.0 & 2.0 & 56 \\
6 & F & 9.3 & 2.2 & 51 \\
7 & F & 9.3 & 2.2 & 52 \\
8 & F & 9.5 & 2.5 & 55 \\
9 & M & 9.5 & 3.5 & 62 \\
10 & F & 10.0 & 1.0 & 62 \\
11 & M & 10.5 & 3.0 & 76 \\
12 & F & 11.3 & 2.0 & 69 \\
13 & M & 11.5 & 4.5 & 104 \\
14 & M & 14.0 & 8.0 & 69 \\
15 & F & 14.5 & 8.5 & 73 \\
16 & F & 14.5 & 7.0 & 85 \\
17 & F & 14.8 & 7.5 & 124 \\
18 & M & 21.0 & 12.0 & 87 \\
& & & & \\
Mean \pm S.E. & & $11.2 \pm 0.8$ & $4.0 \pm 0.8$ & $69 \pm 5$ \\
\hline
\end{tabular}

${ }^{1}$ Max Pdi, maximal transdiaphragmatic pressure.

inspiratory effort while crying against an occluded airway was observed to give maximal values for transdiaphragmatic pressure. Because of the rapid respiratory rates of these infants, it was not possible to consistently occlude the airway at the same lung volume. Clearly, neural drive, lung volume, and diaphragm configuration differed between different airway occlusions. At least 10-20 airway occlusions were measured. The greatest transdiaphragmatic pressure achieved during several attempts at airway occlusion during crying was reported as the maximal Pdi for each subject. All of the infants were awake and were supported in the upright position during measurements.

\section{RESULTS}

Each maximal Pdi reported in "Results" is the greatest Pdi observed in each infant during crying against an occluded airway. For all 38 asymptomatic infants, maximal Pdi ranged from a minimum of $44 \mathrm{cmH}_{2} \mathrm{O}$ to a maximum of $125 \mathrm{cmH}_{2} \mathrm{O}$, with a mean of $72 \pm 3$ (S.E.) $\mathrm{cmH}_{2}$ O. There were no significant differences in the mean maximal Pdi for the infants after repair of abdominal wall defects $\left(79 \pm 7 \mathrm{cmH}_{2} \mathrm{O}\right)$, the infants after repair of congenital diaphragmatic hernia $\left(71 \pm 6 \mathrm{cmH}_{2} \mathrm{O}\right)$, and the infants who had no thoracic or abdominal surgery $\left(69 \pm 5 \mathrm{cmH}_{2} \mathrm{O}\right)$ $(P=0.50)$ (Tables 1,2 , and 3 ). These results indicate that after repair of abdominal wall defects and congenital diaphragmatic hernia the diaphragm is capable of generating comparable maximal transdiaphragmatic pressures to those of nonsurgical infants.

Because there was no difference in maximal Pdi among the three groups of asymptomatic infants, the data from all 38 infants were pooled to evaluate the developmental pattern of diaphragm strength, considered as a function of age postconception (Fig. 1). All infants with a maximal Pdi of less than $60 \mathrm{cmH}_{2} \mathrm{O}$ were at less than 10 months postconceptional age. After 13 months postconceptional age, there was no significant increase in the maximal Pdi. Between the ages of 8-13 months postconception there was a significant positive correlation between maximal $\mathrm{Pdi}$ and age postconception [maximal Pdi $\left(\mathrm{cmH}_{2} \mathrm{O}\right)=$ age $(\mathrm{mpc}) \times 14.6-77$; $r=0.87 ; P<0.0005]$. For the control infants alone, maximal Pdi also increases with postconceptional age [maximal Pdi $\left(\mathrm{CmH}_{2} \mathrm{O}\right)$ $=$ age $(\mathrm{mpc}) \times 11.8-50.6 ; r=0.80 ; P<0.001]$. Maximal transdiaphragmatic pressure also correlated with postnatal age for the control infants $\left[\mathrm{max} \mathrm{Pdi}\left(\mathrm{CmH}_{2} \mathrm{O}\right)=\right.$ age $(\mathrm{mo}) \times 3.83+58.4$; $r=0.60 ; P<0.001]$. These results show a developmental pattern 


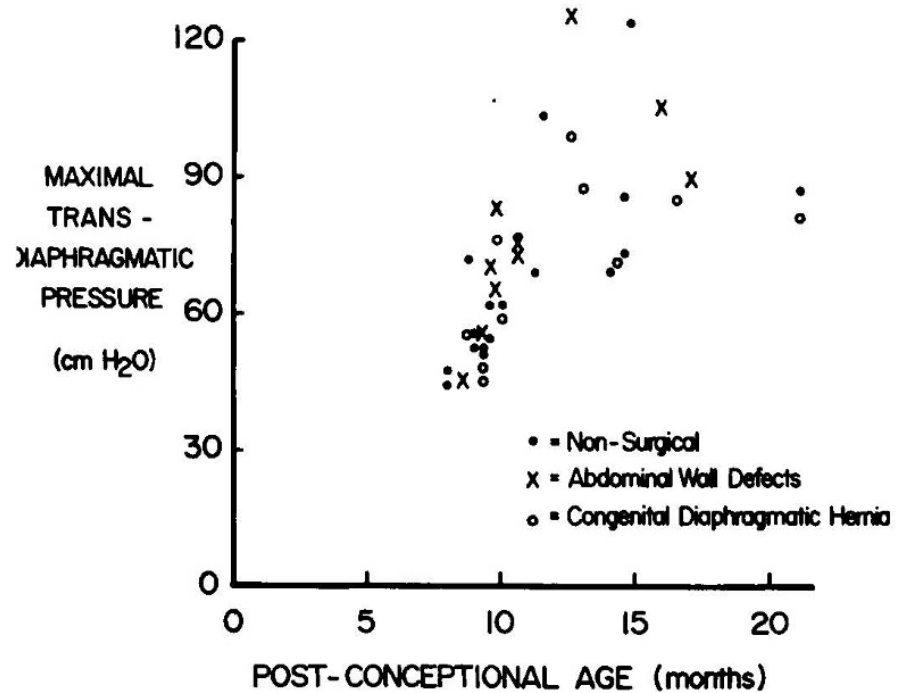

Fig. 1. Diaphragm strength as a function of postconceptional age. Maximal transdiaphragmatic pressure is plotted on the ordinate, and postconceptional age is plotted on the abscissa. Individual data points are shown, with closed circles representing the nonsurgical infants; (X) representing those infants who had repair of abdominal wall defects; and open circles representing those infants who had repair of congenital diaphragmatic hernia.

of increasing maximal transdiaphragmatic pressure in infants during crying.

\section{DISCUSSION}

Like other skeletal muscles, the maximal tension that the diaphragm can generate is influenced by its length (8). Diaphragm function has been shown to be dependent on lung volume, and with hyperinflation its ability to generate maximal inspiratory force is compromised $(7,8)$. Although lung volumes were not measured in these infants, none of them demonstrated hyperinflation on chest roentgenograms. Lung volume undoubtedly varied greatly on different airway occlusions in these infants. Because multiple trials were used in each infant, we assume that the maximal Pdi values occurred at relatively low lung volumes.

When measuring transdiaphragmatic pressure, it was assumed that the diaphragm was relaxed at end expiration during quiet breathing. It has been shown that the diaphragm does generate tonic activity at end expiration (10), but this degree of error is relatively small and should not alter the overall pattern. In contrast, crying involves forced expirations with variations in lung volume. It is possible that the older infants had a more vigorous cry. This would place the diaphragm at a better mechanical advantage and may explain some of the developmental pattern observed. The magnitude of our results are greater than one would expect from changes in lung volume alone $(7,8,12)$.

Crying against an occluded airway did produce the highest Pdi values we observed over $30 \mathrm{~min}$ of recording in these infants. We did not compare these measurements to those obtained during maximal phrenic nerve stimulation. De Troyer and Estenne (4) noted that maximal Pdi can vary considerably depending on whether an inspiratory effort is primarily diaphragmatic or performed with intercostal/accessory muscles. We did not measure the thoraco-abdominal configuration. Changes in this configuration may account for the scatter in values seen above 13 mpc.

This study shows that infants after repair of abdominal wall defects and congenital diaphragmatic hernia are capable of generating maximal transdiaphragmatic pressures equal to infants who have not had surgery.
Maximal transdiaphragmic pressure increases from 8-13 months postconceptional age, reflecting a developmental pattern of increasing diaphragm strength in infancy. Similarly, Shoults $e t$ al. (14) have previously shown that maximal inspiratory force in neonates increases significantly with increasing gestational age. Whether this pattern is entirely due to intrinsic properties of the diaphragm, or is contributed to by chest wall compliance or other factors cannot be determined from our results. De Troyer and Estenne (4) found a maximal Pdi of $91 \pm 8 \mathrm{cmH}_{2} \mathrm{O}$ in 20 normal adults. This is not significantly different from the maximal Pdi of $85 \pm 5 \mathrm{cmH}_{2} \mathrm{O}$ seen in the 10 infants greater than $13 \mathrm{mpc}$. These results suggest that the human diaphragm has strength similar to the adult by 6 months of age. Older infants are also larger. It is possible that nutrition plays a role in our results.

The high compliance of the newborn rib cage results in inward chest wall distortion during inspiration (8). Collapse of the rib cage might limit the magnitude of the negative intrathoracic pressure generated during inspiration, therefore decreasing the maximal transdiaphragmatic pressure. In addition, the mechanical properties of the ventilatory muscles in the neonate are adversely affected by the different angle of insertion of the diaphragm (8). These factors place the diaphragm at a mechanical disadvantage and may contribute to the decreased maximal transdiaphragmatic pressures seen in neonates as compared to older infants.

\section{REFERENCES AND NOTES}

1. Agostoni, E. and Rahn, H.: Abdominal and thoracic pressures at different lung volumes. J. Appl. Physiol., 15: 1087 (1960).

2. Agostoni, E.: A graphical analysis of thoraco-abdominal mechanics during the breathing cycle. J. Appl. Physiol., 16: 1055 (1961).

3. Beardsmore, C. S., Helms, P., Stocks, J., Hatch, D. J., and Silverman, M.: Improved esophageal balloon technique for use in infants. J. Appl. Physiol.: Respir. Environ. Exercise Physiol., 49: 735 (1980).

4. De Troyer, A. and Estenne, M.: Limitations of measurement of transdiaphragmatic pressure in detecting diaphragmatic weakness. Thorax, 36: 169 (1981).

5. Hilberman, M., Kamm, B., Lamy, M., Dietrich, H. P., Martz, K., and Osborn, J. J.: An analysis of potential physiological predictors of respiratory adequacy following cardiac surgery. J. Thor. Cardio. Surg., 71: 711 (1976).

6. Keens, T. G., Bryan, A. C., Levison, H., and Lanuzzo, C. D.: Developmental pattern of muscle fiber types in human ventilatory muscles. J. Appl. Physiol.: Respirat. Environ. Exercise Physiol., 44: 909 (1978).

7. Minh, V.-D., Dolan, G. F., Konopka, R. F., and Moser, K. M.: Effect of hyperinflation on inspiratory function of the diaphragm. J. Appl. Physiol., 40: 67 (1976).

8. Muller, N. L. and Bryan, A. C.: Chest wall mechanics and respiratory muscles in infants. Pediatr. Clin. N. Am., 26: 503 (1976).

9. Muller, N., Gulston, G., Cade, D., Whitton, J., Froese, A. B., Bryan, M. H., and Bryan, A. C.: Diaphragmatic muscle fatigue in the newborn. J. Appl. Physiol.: Respir. Environ. Exercise Physiol., 46: 688 (1979).

10. Muller, N., Volgyesi, G., Becker, L., Bryan, M. H., and Bryan, A. C.: Diaphragmatic muscle tone. J. Appl. Physiol.: Respir. Environ. Exercise Physiol., 47: 279 (1979).

11. Muller, N., Volgyesi, G., Bryan, M. H., and Bryan, A. C.: The consequences of diaphragmatic muscle fatigue in the newborn infant. J. Pediatr., 95: 793 (1979).

12. Nickerson, B. G. and Keens, T. G.: Measuring ventilatory muscle endurance in humans as the sustainable inspiratory pressure. J. Appl. Physiol.: Respir. Environ Exercise Physiol., S2: 768 (1982).

13. Roussos, C. S. and Macklem, P. T.: Diaphragmatic fatigue in man. J. Appl. Physiol., 43: 189 (1977).

14. Shoults, D., Clark, T. A., Benumof, J. L., and Mannino, F. L.: Maximum inspiratory force in predicting successful neonate tracheal extubation. Crit. Care Med., 7: 485 (1979).

15. Bruce G. Nickerson, M.D., was the recipient of a California Lung Association Fellowship Training Grant, 1979-81. This study was supported in part by NIH Biomedical Research Support Grant S07RR05469-17.

16. The authors wish to thank Dr. Morton M. Woolley, Chief of Pediatric Surgery, for his assistance and encouragement; and Helmi K. Haines for preparation of the manuscript.

17. This work was presented in part before the Annual Meeting of the Society for Pediatric Research, San Francisco, California, May, 1981.

18. Requests for reprints should be addressed to: Dr. Thomas G. Keens, NeonatalRespiratory Disease Division, Childrens Hospital of Los Angeles, 4650 Sunset Boulevard, Los Angeles, California 90027.

19. Received for publication August 5, 1982.

20. Accepted for publication December 9, 1982. 